\title{
Pengaruh Sikap Kerja Duduk Terhadap Keluhan Cumulative Trauma Disorders (CTDs) Pada Pekerja Bagian Sewing di CV. Eka Braja Paksi Garment Klaten
}

\section{The Effect of Sit Work Attitudes Related to Complaints of Cumulative Trauma Disorders (CTDs) On Sewing Workers at CVEka Braja Paksi Garment Klaten.}

\author{
Mita Margiana ${ }^{1}$, Wartini², Titik Haryanti $^{3}$ \\ Program Studi Kesehatan Masyarakat, Universitas Veteran Bangun Nusantara ${ }^{1,2,3}$ \\ Email :mitaamrgn919@gmail.com
}

\begin{abstract}
Sewing work carried out with sit work attitudes. Continously sit work attitudes and poor sit work attitudes can cause muscle complaints and potentially caused complaints of Cumulative Trauma Disorders. According to preliminary survey at CV. Eka Braja Paksi, by 10 workers, there is $80 \%$ of workers with pain complaints on back, shoulder, neck, wrist and buttock. While $20 \%$ of workers doesn't feel any sick complaints or pain on any part of body. This Study aims to determine the The Effect of sit work attitudes related to complaints of Cumulative Trauma Disorders on Sewing workers.

The type of this research is analytical survey with cross sectional approach held on july 2020. The research sample's on Sewing is 40 respondent. Independent variable is sit work attitudes. Dependent variable is Complaints of Cumulative Trauma Disorders. The instrument use Questionaire of sit work attitudes, Questionaire Nordic Body Map, measurement of body mess and height meter.

The result of chi square test showed that $50 \%$ of workers worked with poor sit work attitudes and 27,5\% and 42,5\% of workers experience complaints of Cumulative Trauma Disorders category middle and high. Based on chi square test research, there is effect related to complaints of Cumulative Trauma Disorders $\mathrm{p}$ values $=0,000 \mathrm{C}=0,653$.

Recommended to provide an ergonomic chair according to the worker's antropometric measurements. Strecth muscles and other body parts in a standing posture for 5 minutes every 1 hour. Provide a first aid kit for workers who experience aches or work accidents can immedietly be given first aid.
\end{abstract}

Keyword: Complaints Cumulative Trauma Disorders, sit work attitudes.

\begin{abstract}
ABSTRAK
Pekerjaan menjahit dilakukan dengan sikap kerja duduk, sikap kerja duduk yang terlalu lama dan tidak baik dapat menimbulkan keluhan otot dan berpotensi mengalami keluhan Cumulative Trauma Disorders. Berdasarkan survei pendahuluan di CV. Eka Braja Paksi yang dilakukan, dari 10 pekerja terdapat $80 \%$ pekerja mengalami keluhan nyeri, sedangkan $20 \%$ pekerja tidak merasakan keluhan sakit atau nyeri dibagian tubuh tertentu. Penelitian ini bertujuan untuk mengetahui pengaruh sikap kerja duduk terhadap keluhan Cumulative Trauma Disorders pada pekerja Sewing di CV. Eka Braja Paksi Garmen.

Jenis penelitian ini adalah survei analitik dengan pendekatan Cross Sectional. Dilaksanakan pada bulan Juli 2020 dengan sampel sebanyak 40 responden. Variabel bebas penelitian ini yaitu Sikap kerja duduk dan variabel terikat adalah keluhan Cumulative Trauma Disorders. Instrumen yang digunakan yaitu kuesioner sikap kerja duduk dan Nordic Body Map serta timbangan injak dan meteran untuk mengukur IMT. Uji analisis data yang digunakan uji Chi Square.

Hasil penelitian menunjukkan 50\% pekerja bekerja dengan sikap kerja duduk tidak baik. 27,5\% responden mengalami keluhan CTDs sedang dan $42,5 \%$ responden mengalami keluhan CTDs kategori tinggi. Berdasarkan uji chi square ada pengaruh antara sikap kerja duduk terhadap keluhan CTDs ( $p$ value $=0,000$. $\mathrm{C}=0,653)$.

Disarankan untuk menyediakan kursi yang ergonomis sesuai dengan ukuran antropometri pekerjanya, melakukan peregangan otot dan bagian tubuh lainnya dengan sikap berdiri selama 5 menit dalam setiap $1 \mathrm{jam}$, dan menyediakan kotak P3K supaya pekerja yang mengalami pegal atau kecelakaan kerja dapat segera diberikan pertolongan pertama.
\end{abstract}

Kata Kunci : Keluhan Cumulative Trauma Disorders (CTDs), Sikap kerja duduk. 


\section{PENDAHULUAN}

Industri tekstil merupakan sektor yang memberikan kontribusi besar bagi perekonomian nasional, sebab industri tekstil tergolong padat karya dan berorientasi ekspor. Garmen merupakan bagian terbesar dari industri tekstil untuk penyerapan tenaga kerja yang banyak. Industri tekstil merupakan sektor yang memberikan kontribusi besar bagi perekonomian nasional, sebab industri tekstil tergolong padat karya dan berorientasi ekspor. (Kemenperin, 2018).

Garmen merupakan bagian terbesar dari industri tekstil untuk penyerapan tenaga kerja yang banyak. Sikap kerja duduk dalam durasi waktu yang lama dapat menimbulkan sikap kerja tidak alamiah, sehingga digunakan untuk merelaksasikan otot namun dalam waktu yang lama dapat menyebabkan masalah - masalah punggung dan menimbulkan permasalahan sirkulasi darah di kaki serta terjadi gangguan kesehatan. Berdasarkan sudut pandang ergonomi, aktivitas pekerjaan yang berulang - ulang dan berlangsung lama menimbulkan risiko terjadinya Cumulative Trauma Disorders (CTDs) (Tarwaka, 2004).

Cumulative Trauma Disorders (CTDs) yang berkepanjangan menimbulkan kecacatan dan mengakibatkan berkurangnya ketrampilan dalam melaksanakan pekerjaan, produktivitas kerja menurun dan tingginya absensi pada pekerja. (Harrianto, 2010). International Labour Organization (ILO) dalam program The Prevention of Occupational Diseases mengatakan 27 negara di bagian Uni Eropa, kasus Musculoskeletal Disorders (MSDs) merupakan penyakit yang paling umum yang berhubungan dengan gangguan kesehatan saat bekerja (ILO, 2013). Pada survey yang dilakukan di Great Britani tercatat bahwa angka kejadian MSDs sebesar 41\% dari angka kejadian penyakit akibat kerja, dan penyakit MSDs menjadi 37\% penyebab seseorang absen dalam pekerjaan (HSE, 2016). Negara berkembang seperti Indonesia, angka prevalensi gangguan Musculoskeletal Disorders (MSDs) sebesar 24,7\% (Riskesdas, 2013). Berdasarkan hasil laporan mengenai situasi kesehatan kerja tahun 2015 jumlah kasus penyakit akibat kerja tahun 2014 sebanyak 40.694 kasus. Penduduk yang bekerja dan memiliki keluhan kesehatan menurut lapangan usaha industri pengolahan berada diperingkat 3 dengan persentase 24, 84\% (Kementerian Kesehatan RI, 2015). Kasus penyakit musculoskeletal di Kabupaten Klaten sebanyak 35,4\%. Kabupaten Klaten merupakan salah satu kabupaten di Provinsi Jawa Tengah yang memiliki 53 perusahaan yang bergerak dibidang garmen (BPS Kabupaten Klaten, 2017). Berdasarkan data di Wilayah kerja Puskesmas wonosari II bulan januari - maret 2020 memiliki angka keluhan musculoskeletal sebanyak 522 orang, 167 diantaranya laki - laki dan 355 perempuan (Puskesmas Wonosari II, 2020).

CV. Eka Braja Paksi merupakan perusahaan yang yang bergerak dibidang garment dan mendapat julukan sebagai specialist outdoor dimata para buyer dan merupakan perusahaan garmen yang menerima CMT (Cut Make and Trim) dan FOB (Free On Board) dalam skala besar maupun kecil. Perusahaan tersebut memiliki pekerja sebanyak 90 pekerja, pada bagian Sewing sebanyak 50 orang dengan target produksi setiap bulannya 5000 - 25.000 hasil produksi sehingga bagian Sewing di CV. Eka Braja Paksi Garmen merupakan faktor terpenting yang perlu diteliti karena memiliki banyak pekerjaan.

Berdasarkan hasil survei pendahuluan yang dilakukan di CV. Eka Braja Paksi Garmen pada tanggal 13 April 2020 untuk mengetahui sikap kerja duduk dan gejala Cumulative Trauma Disorders (CTDs) dibagian Sewing sebanyak 10 pekerja dengan menggunakan kuesioner sikap kerja dan Nordic Body Map (NBM) yang diberikan kepada 10 pekerja dibagian Sewing terdapat $70 \%$ orang yang bekerja pada posisi duduk tidak baik yaitu sikap duduk membungkuk sehingga menyebabkan tulang belakang melengkung dan tidak diselingi dengan aktivitas berjalan, sedangkan $30 \%$ orang bekerja pada posisi duduk 
yang baik yaitu dengan duduk tegak dan diselingi dengan aktivitas berjalan. Terdapat $80 \%$ pekerja dengan keluhan nyeri pada bagian punggung, bahu, leher, pergelangan tangan dan bagian pantat, sedangkan $20 \%$ pekerja tidak merasakan keluhan.

Berdasarkan fakta masalah di atas, menjadi dasar latar belakang bagi peneliti untuk melakukan penelitian mengenai Pengaruh sikap kerja duduk terhadap gejala Cumulative Trauma Disorders (CTDs) pada tenaga kerja bagian Sewing di CV. Eka Braja Paksi Garmen, Klaten.

\section{METODE}

Jenis dan rancangan penelitian yang digunakan dala penelitian ini yaitu Penelitian Survei Analitik dengan pendekatan Cross Sectional. Penelitian dilaksanakan pada bulan Juli 2020 dibagian Sewing di CV. Eka Braja Paksi Garmen. Populasi dalam penelitian ini adalah tenaga kerja bagian Sewing di CV. Eka Braja Paksi Garmen sejumlah 50 responden. Sampel pada penelitian menggunakan Non Random Sampling dengan teknik pengambilan sampel secara Purposive Sampling yang merupakan teknik pengambilan sampel berdasarkan pertimbangan tertentu yang telah dibuat oleh peneliti, berdasarkan ciri atau sifat - sifat populasi yang sudah diketahui sebelumnya (Agus Riyanto, 2011). Penjaringan sampel dari populasi 50 responden yang terdiri dari 1 pekerja laki - laki dan 49 pekerja perempuan didapatkan sampel yang memenuhi kriteria subjek penelitian sebanyak 40 responden.

Variabel bebas dalam penelitian ini yaitu sikap kerja duduk. Variabel terikat dalam penelitian ini yaitu Keluhan Cumulative Trauma Disorders (CTDs). Variabel penganggu dalam penelitian ini meliputi umur, jenis kelamin, ukuran tubuh (IMT), kesehatan, getaran, mikrolimat, gerakan berulang, sikap paksa tubuh dan peralatan yang tidak sesuai.

Instrumen dalam penelitian ini meliputi kuesioner sikap kerja duduk dan kuesioner Nordic Body Map, timbangan injak guna pengukuran berat badan dan meteran (Microtoise Staturmater) guna pengukuran tinggi badan untuk mengukur IMT responden.

Uji statistik pada penelitian ini menggunakan uji statistik Chi Square dengan tingkat signifikan 95\% (Sugiyono, 2013) yaitu : Nilai $p$ value $\leq 0,05$ maka Ho ditolak, yang berarti ada pengaruh yang signifikan antara variabel bebas dengan variabel terikat. Nilai $\mathrm{p}$ value $>$ 0,05 maka Ho diterima, yang berarti tidak ada pengaruh yang signifikan antara variabel bebas dengan variabel terikat. Uji korelasi koefisien kontingensi merupakan analisis uji yang digunakan untuk menentukan seberapa kuat korelasi variabel bebas terhadap variabel terikat (Sugiyono, 2013).

\section{HASIL DAN PEMBAHASAN}

\section{ANALISIS UNIVARIAT}

\section{Sikap Kerja Duduk}

Hasil penelitian mengenai sikap kerja duduk pada pekerja Sewing di CV. Eka Braja Paksi Garment dengan menggunakan kuesioner sikap kerja duduk sebanyak 15 pertanyaan sebagai berikut:

Tabel 1. Distribusi Frekuensi Sikap Kerja Duduk

\begin{tabular}{ccc}
\hline Sikap Kerja Duduk & Frekuensi & Persentase \\
\hline Baik & 20 & $50 \%$ \\
Tidak Baik & 20 & $50 \%$ \\
\hline Jumlah & 40 & $100 \%$ \\
\hline
\end{tabular}


Berdasarkan tabel 1. menunjukkan bahwa dari 40 responden atau $100 \%$ yang diteliti responden dengan kategori sikap kerja duduk yang tidak baik sebanyak 20 pekerja atau $50 \%$ begitu juga responden dengan kategori sikap kerja duduk yang baik sebanyak 20 pekerja atau $50 \%$.

Berdasarkan data distribusi frekuensi sikap kerja duduk terdapat 26 responden atau 65\% responden menunjukkan sikap kerja tidak baik yaitu kursi yang digunakan tidak nyaman, bekerja dengan posisi membungkuk, tidak menyelingi pekerjaan dengan aktivitas berjalan (peregangan) dan tidak memiliki ruang gerak yang leluasa ketika bekerja.

Terdapat 33 responden atau 82,5\% responden menggunakan kursi yang tidak memiliki sandaran punggung, bantalan karet. Sedangkan 7 responden atau 17,5\% menggunakan kursi yang tidak memiliki sandaran punggung, bantalan karet dan kaki menggantung di kursi karena kursi terlalu tinggi untuk responden saat bekerja sehingga menyebabkan banyak responden mengalami keluhan Cumulative Trauma Disorders (CTDs).

\section{Keluhan Cumulative Trauma Disorders (CTDs)}

Hasil penelitian mengenai penilaian keluhan Cumulative Trauma Disorders (CTDs) dilakukan dengan menggunakan Nordic Body Map, hal ini dilakukan guna melihat adakah keluhan Cumulative Trauma Disorders (CTDS) pada tenaga kerja bagian Sewing di CV. Eka Braja Paksi Garment. Jumlah bagian tubuh yang akan dinilai sebanyak 28 bagian sebagai berikut:

Tabel 2. Keluhan Cumulative Trauma Disorders (CTDS)

\begin{tabular}{cccc}
\hline No & Keluhan $\boldsymbol{C T D S}$ & Frekuensi & Persentase \\
\hline $\mathbf{1}$ & Rendah & 12 & $30 \%$ \\
$\mathbf{2}$ & Sedang & 11 & $27,5 \%$ \\
$\mathbf{3}$ & Tinggi & 17 & $42,5 \%$ \\
\hline & Jumlah & 40 & $100 \%$ \\
\hline
\end{tabular}

Berdasarkan tabel 2. menunjukkan bahwa dari 40 responden atau $100 \%$ yang diteliti responden dengan keluhan Cumulative Trauma Disorders (CTDs) kategori rendah sebanyak 12 responden atau 30\%, keluhan Cumulative Trauma Disorders (CTDs) kategori sedang sebanyak 11 responden atau 27,5\%, keluhan Cumulative Trauma Disorders (CTDs) kategori tinggi sebanyak 17 responden atau 42,5\%.

Berdasarkan data distribusi frekuensi keluhan Cumulative Trauma Disorders (CTDs) terdapat 34 responden atau 85\% yang mengeluh sakit dibagian pantat, kaku di leher, pinggang,punggung, bahu, dan pergelangan tangan. Sedangkan 6 responden atau $15 \%$ mengeluh sakit dibagian lengan atas, paha, lutut, tangan dan kaki.

\section{ANALISIS BIVARIAT}

Analisis bivariat merupakan analisis yang melibatkan dua variabel guna mengetahui ada tidaknya pengaruh antara sikap kerja duduk terhadap keluhan Cumulative Trauma Disorders (CTDs). Uji statistik yang digunakan yaitu uji Chi Square dengan korelasi koefisien kontingensi.

\section{Pengaruh Antara Sikap Kerja Duduk Terhadap Keluhan Cumulative Trauma Disorders (CTDs)}

Tabel 3. Pengaruh Sikap Kerja Terhadap keluhan Cumulative Trauma Disorders (CTDs) 


\begin{tabular}{lccccccccccc}
\hline No & $\begin{array}{c}\text { Sikap Kerja } \\
\text { Duduk }\end{array}$ & \multicolumn{10}{c}{ Keluhan $\boldsymbol{C T D s}$} \\
\cline { 3 - 11 } & & Rendah & Sedang & Tinggi & Total & P value & C \\
\hline & & F & $\%$ & f & $\%$ & F & $\%$ & F & $\%$ & & \\
\cline { 3 - 12 } & & & & & & & & & & & \\
$\mathbf{1}$ & Tidak Baik & 1 & 8,3 & 2 & 18,2 & 17 & 100 & 20 & 50,0 & 0,000 & 0,653 \\
$\mathbf{2}$ & Baik & 11 & 91,7 & 9 & 81,8 & 0 & 0 & 20 & 50,0 & & \\
\hline & Total & 12 & 100 & 11 & 100 & 17 & 100 & 40 & 100 & & \\
\hline
\end{tabular}

Berdasarkan tabel 3. Pekerja yang mengalami keluhan Cumulative Trauma Disorders (CTDs) rendah sebanyak 12 responden (30\%) dengan sikap kerja duduk tidak baik yaitu 1 responden (8,3\%). Keluhan Cumulative Trauma Disorders (CTDs) sedang sebanyak 11 responden $(27,5 \%)$ dengan sikap kerja duduk tidak baik yaitu 2 responden (18,2\%), dan keluhan Cumulative Trauma Disorders (CTDs) tinggi sebanyak 17 responden dengan sikap kerja duduk tidak baik sebanyak 17 responden $(42,5 \%)$.

Hasil uji Chi square pada Asymp. Sig. (2-sided) sebesar 0,000, yang berarti nilai $p$ value $<0,05$ sehingga Ho ditolak yang artinya ada pengaruh antara sikap kerja duduk terhadap keluhan Cumulative Trauma Disorders (CTDs) pada pekerja bagian Sewing di CV. Eka Braja Paksi Garment. Nilai analisis Contingency Coeficient (C) didapatkan nilai sebesar 0,653 yang berarti pengaruh antara sikap kerja duduk terhadap keluhan Cumulative Trauma Disorders (CTDs) pada pekerja bagian Sewing di CV. Eka Braja Paksi Garment memiliki tingkat pengaruh yang kuat dengan interval koefisien 0,600-0,790.

Hasil analisis uji Chi Square didapatkan p value sebesar 0,000 menunjukkan adanya pengaruh yang signifikan antara sikap kerja duduk terhadap keluhan Cumulative Trauma Disorders (CTDs) dengan keeratan (C) 0,653. Distribusi tersebut secara deskriptif menunjukkan bahwa frekuensi sikap kerja duduk mempengaruhi keluhan Cumulative Trauma Disorders (CTDs).

Hasil penelitian ini sebanding dengan penelitian Diandra Arisnawati, 2017 yang berjudul Hubungan Postur Kerja Dengan Keluhan Cumulative Trauma Disorders (CTDs) Pada Pekerja Pelintingan Rokok Manual Di Pt. Panen Boyolali Tahun 2017 dengan nilai $p$ value 0,000 dan r 0,475 yang berarti terdapat pengaruh antara Postur Kerja Dengan Keluhan Cumulative Trauma Disorders (CTDs) Pada Pekerja Pelintingan Rokok Manual Di PT. Panen Boyolali.

Keluhan Cumulative trauma disorders (CTDS) yang dialami oleh pekerja bagian Sewing di CV. Eka Braja Paksi Garmen menunjukkan bahwa pekerja bekerja dengan sikap kerja yang tidak baik terutama akibat penggunaan kursi yang tidak ergonomis seperti kursi tanpa sandaran punggung yang menyebabkan pekerja duduk dengan posisi membungkuk, tidak ada bantalan karet dan tidak ada pijakan kaki. Hal tersebut menyebabkan nyeri otot dan punggung serta gangguan fungsi otot lainnya.

Keluhan Cumulative Trauma Disorders (CTDs) sekumpulan gangguan atau kekacauan pada system Muskuloskeletal (Musculosceletal disorders) berupa cedera pada syaraf, otot, tendon, ligament, tulang dan persendian pada titik - titik ekstrim tubuh bagian atas (tangan, pergelangan, siku, dan bahu), tubuh bagian bawah (kaki, lutut, dan pinggul), dan tulang belakang yang meliputi punggung dan leher.

Cumulative Trauma Disorders (CTDS) dapat mengakibatkan kecacatan pada pekerja, karena selain rasa nyeri yang ditimbulkan dapat menyebabkan pembatasan fungsi - fungsi anggota tubuh sehingga berpengaruh terhadap pekerjaa sehari - hari. Selain menyebabkan kecacatan pada pekerja, penderita Cumulative Trauma Disorders (CTDS) juga dapat menimbulkan kerugian bagi tempat kerja meliputi menurunnya produktivitas, 
pengeluaran perusahaan meningkat dalam bentuk biaya pengobatan ataupun pembayaran ganti rugi karena keterbatasan dan kecacatan pekerja (Hastuti, 2011).

\section{KESIMPULAN}

Pekerja pada bagian Sewing di CV. Eka Braja Paksi Garment dengan sikap kerja tidak baik sebanyak 20 pekerja (50\%). Pekerja pada bagian Sewing di CV. Eka Braja Paksi Garment yang mengalami keluhan Cumulative Trauma Disorders (CTDs) sebanyak 28 pekerja diantaranya 11 pekerja mengalami keluhan Cumulative Trauma Disorders (CTDs) kategori sedang $(27,5 \%)$ dan 17 pekerja mengalami keluhan Cumulative Trauma Disorders (CTDs) kategori tinggi (42,5\%). Terdapat pengaruh antara sikap kerja duduk terhadap keluhan Cumulative Trauma Disorders (CTDs) pada pekerja bagian Sewing di CV. Eka Braja Paksi Garment dengan hasil p value $0,000 \leq 0,05$ dan nilai contingency coefficient (C) yaitu 0,653 yang berarti memiliki pengaruh yang kuat.

\section{SARAN}

CV. Eka Braja Paksi Garment disarankan untuk menyediakan kursi yang memiliki sandaran punggung dan bantalan karet atau bisa dengan melakukan rekayasa teknik yaitu menggunakan pijakan kaki seperti bangku kecil supaya kaki pekerja bagian Sewing tidak menggantung di lantai. Mengadakan peregangan otot dan bagian tubuh lainnya dengan sikap berdiri selama 5 menit dalam setiap 1 jam dan mengadakan senam minimal 15 menit setiap satu minggu sekali. Memasang poster sikap kerja duduk yang benar dan panduan gerakan peregangan. Menyediakan kotak P3K di setiap bagian supaya pekerja yang mengalami pegal atau kecelakaan kerja dapat segera diberikan pertolongan pertama

\section{DAFTAR PUSTAKA}

BPS Klaten. 2017. Kelompok Sentra Industri dan Jumlah Unit Usaha Menurut Bidang Usaha di Kabupaten Klaten Tahun 2017. https://klatenkab.bps.go.id/statictable/2019/01/30/328/kelompok-sentrain dustri-dan-jumlah-unit-usaha-menurut-bidang-usaha-di-kabupatenklaten

Hastuti. R. P. 2011. Cumulative Trauma Disorders Pada Tenaga Kerja Bagian Penjahit Konveksi Aneka Gunungpati Semarang. Skripsi. UNNES

Health and Safety Executive. 2016. Manual Handling Operation Regulation 1992. Norwich: British Standar

ILO (International Labour Organization). 2013. The Prevention of Occupational Diseases. $\quad$ https://www.ilo.org/safework/info/WCMS_208226/langen/index.htm. (Diakses pada 09 April 2020).

Iridiastadi, Hardianto dan Yassierli. 2014. Ergonomi Suatu Pengantar. Bandung: PT. Remaja Rosdakarya

Kementerian Kesehatan RI. 2013. Riskesdas Tahun 2013. http://kesga.kemkes.go.id/images/pedoman/Data\%20Riskesdas\%202013.pdf.

(Diakses Pada 06 April 2020) 
$\begin{array}{cccc}\text { 2018. Klasifikasi } \quad \text { Obesitas } & \text { Setelah Pengukuran } & \text { IMT. } \\ \text { (http://p2ptm.kemkes.go.id/infographic-p2ptm/obesitas/klasifikasiobesi } & \\ \text { tas-setelah-pengukuran-imt). (Diakses Pada 18 April 2020) } & \end{array}$

Kementerian Perindustrian RI. 2019. Industri Tekstil Jadi Sektor Strategis. https://www.kemenperin.go.id/artikel/21405/Menperin:-Industri- Tekstil -Jadi Sektor-Strategis. (Diakses Pada 05 April 2020).

Pusat Data dan Informasi Kemenkes RI. 2015. Situasi Kesehatan Kerja 2015. https://www.kemkes.go.id/download.php?file=download/pusdatin/in fodatin/infodatin-kesja.pdf. (Diakses pada 10 April 2020)

.2018. InfoDatin K3 (Kesehatan dan Keselamatan Kerja).https://pusdatin.kemkes.go.id/article/view/18100400001/infodatinkeselamatan-dan-kesehatan-kerja.html. (Diakses pada 10 April 2020).

Riyanto, A. 2011. Aplikasi Metodologi Penelitian Kesehatan. Yogyakarta: CV.Nuha Medika.

Salvendy. 2012. Handbook of Human Factors and Ergonomics. $3^{\text {rd }}$ Ed. Jhon Willey and Sons, Inc. United States of America

Tarwaka, Sholichul, Lilik Sudiajeng. 2004. Ergonomi untuk Keselamatan Kerja dan Produktivitas. Surakarta: Uniba Press

- 2013. Ergonomi Industri. Surakarta: Harapan Press Surakarta

- 2015. Ergonomi Industri Dasar - Dasar Pengetahuan Ergonomi dan Aplikasi di Tempat Kerja. Surakarta: Harapan Press Surakarta. 